\title{
Penerapan Irigasi Tetes Emiter Tali Dengan Bebagai Selang Waktu Irigasi Pada Tanaman Semangka
}

\section{Application the Drip Irrigation with Nylon Rope Emitter on Different Irrigation Intervals for Cultivation of Watermelon}

\section{Muhammad Idrus* dan Surya}

${ }^{1}$ Dosen Politeknik Negeri Lampung

*E-mail : idrusmuhammad62@polinela.ac.id

\begin{abstract}
The objectives of the research were (1) To know watermelon yield and irrigation water productivity of watermelon by used drip irrigation with nylon rope emitter on various time irrigation intervals, (2) To determined the good time irrigation interval for watermelon production by using the drip irrigation with nylon rope emitter. The research was conducted at the research field with four-time irrigation intervals were 1,2,3, and 4 days of time irrigation interval. The research was arranged in Completely Randomized Block Design. The result of the research showed that the time irrigation interval was not significantly affected yield and irrigation water productivity of watermelon. The soil moisture in the root zone at $30 \mathrm{~cm}$ depth of 23,23-23,88\% before irrigation still in range of the available soil moisture content for plants. The average of watermelon yield and irrigation water productivity of watermelon were 5,07-5,45 kg/plant and 115,15-123,79 kg/m $\mathrm{m}^{3}$. The good time interval of irrigation for watermelon production by using drip irrigation with rope emitter was 4 days time interval of irrigation.
\end{abstract}

Keywords : Drip irrigation with nylon rope emitter, time irrigation interval, yield and water productivity of watermelon.

Disubmit : 20 Januari 2019; Diterima: 03 Maret 2019; Disetujui : 10 April 2019

\section{PENDAHULUAN}

Tanaman semangka merupakan tanaman yang berumur relatif singkat, digemari masyarakat karena buahnya yang manis dan banyak mengandung air, serta daya tarik budidaya bagi petani terletak pada nilai ekonomi yang tinggi. Provinsi Lampung merupakan salah satu sentra produksi semangka di Indonesia yang menyebar di 10 wilayah kabupaten yang luasnya mencapai 1.370 ha (Badan Pusat Statistik, 2018). Tanaman semangka merupakan tanaman yang memerlukan lama penyinaran matahari yang penuh dan air yang banyak untuk keberlangsungan proses fotosintesa sehingga tanaman semangka banyak ditanam di musim kemarau dimana pada umumnya daerah-daerah di Indonesia mempunyai cadangan air permukaan tersedia dalam jumlah terbatas. Oleh karena itu penggunaan air untuk pemenuhan kebutuhan air tanaman pada umumnya dan tanaman semangka pada khususnya perlu sehemat mungkin agar cadangan air yang terbatas dapat cukup sampai tanaman yang diusahakan selesai dipanen.

Salah satu cara penggunaan air secara hemat untuk pemenuhan kebutuhan atanaman semangka yaitu dengan menggunakan teknologi irigasi hemat air berupa irigasi tetes atau irigasi sprinkler. Irmak et al., (2011) mengemukakan bahwa efisiensi pemakaian air irigasi tetes dapat mencapai 95\%, sedangkan irigasi sprinkler hanya dapat mencapai $85 \%$. Selanjutnya, efisinesi pemakaian air irigasi tetes dengan menggunakan 2, 4, dan 5 buah emiter per tanaman pisang berturut-turut 82, 88, dan 92\% (Jadavi et al., 2013). 
Pejić et al., (2016) melaporkan bahwa produksi semangka yang diirigasi rata-rata 37,28 t/ha secara nyata lebih tinggi dibandingkan dengan tanpa irigasi yang hanya rata-rata 9,98 t/ha. Selanjutnya dikatakan bahwa produktivitas air irigasi tanaman semangka dan efisiensi pengunnaan air untuk evapotranspirasi berturut-turut 9,93 dan 10,29 kg/m ${ }^{3}$. Rashidi \& Gholami, (2008) melaporkan bahwa produktivitas air tanaman semangka berkisar $2,70-14,33 \mathrm{~kg} / \mathrm{m}^{3}$ dan produksi semangka berkisar $14.630-47.420 \mathrm{~kg} / \mathrm{ha}$ dengan evapotranspirasi aktual tanaman (ETc) semangka 174,48 - 1.191,69 mm. Pasaribu, Sumono, Daulay, dan Susanto (2013) melaporkan bahwa kebutuhan air tanaman (ETc) semangka adalah 2,80 mm/hari untuk fase awal pertumbuhan, $6,23 \mathrm{~mm} /$ hari untuk fase tengah pertumbuhan, dan $4,36 \mathrm{~mm} /$ hari untuk fase akhir pertumbuhan.

Pada kondisi evaporasi tinggi dan curah hujan rendah selang waktu irigasi tanaman semangka biasanya 7-10 hari (FAO, 2017a). Penelitian tentang selang waktu pemberian air irigasi pada tanaman semangka 1 hari, 2 hari, 3 hari dan 4 hari telah dilakukan oleh (Fernandes et al., 2014). Hasil penelitian menunjukkan bahwa selang waktu irigasi lebih dari 1 hari berpengaruh nyata terhadap penurunan produksi tanaman semangka pada tanah pasir dengan menggunakan irigasi tetes.

Selanjutnya penelitian tentang selang waktu irigasi pada tanaman semangka dengan selang waktu irigasi 4, 6, 8, dan 10 hari dengan menggunakan irigasi tetes bawah permukaan telah dilakukan dengan hasil selang waktu irigasi berpengaruh nyata terhadap produksi dan produktivitas air irigasi tanaman semangka (Idrus et al., 2012). Berdasarkan selang waktu irigasi tanam semangka yang telah dikemukakan timbul pertanyaan apakah selang waktu irigasi tanaman semangka 2 hari, 3 hari, dan 4 hari pada tanah liat akan berpengaruh nyata terhadap penurunan produksi semangka? Untuk menjawab pertanyaan ini maka diperlukan penelitian selang waktu irigasi tersebut pada budidaya semangka.

Tujuan penelitian yaitu (1) untuk mengetahui produktivitas air irigasi tanaman semangka pada berbagai selang waktu irigasi dengan menggunakan irigasi tetes emiter tali, dan (2) untuk menentukan selang waktu irigasi yang baik untuk tanaman semangka dengan menggunakan irigasi tetes emiter tali.

\section{METODE PENELITIAN}

Penelitian telah dilakukan di Kebun Percobaan Politeknik Negeri Lampung. Bahan utama penelitian terdiri dari pipa PVC, lem PVC, benih semangka Aura Merah F1, pupuk Urea, Pupuk KCl, pupuk TSP, obatobatan dan lain-lain.

Alat yang digunakan adalah ember, bak penampung air, pompa irigasi, cangkul, golok, bor listrik, gergaji, stopwatch, knapsack sprayer, timbangan dan lain-lain.

Emiter tali dirancang bangun dari selang plastik berdiameter dalam $5 \mathrm{~mm}$ dan tali plastik berdiameter luar $5 \mathrm{~mm}$ dimasukkan ke dalam lubang selang plastik, yang panjangnya $2 \mathrm{~cm}, 3 \mathrm{~cm}$, dan $4 \mathrm{~cm}$ (Idrus, Darmaputra dan Surya, 2014) seperti pada Gambar 1. Emiter tali merupakan komponen alat irigasi tetes emiter tali yang berfungsi mengucurkan air ke areal perakaran tanaman semangka. Serabut-serabut tali plastik berfungsi untuk menurunkan tekanan aliran yang keluar emiter tali agar air keluar secara menetes.

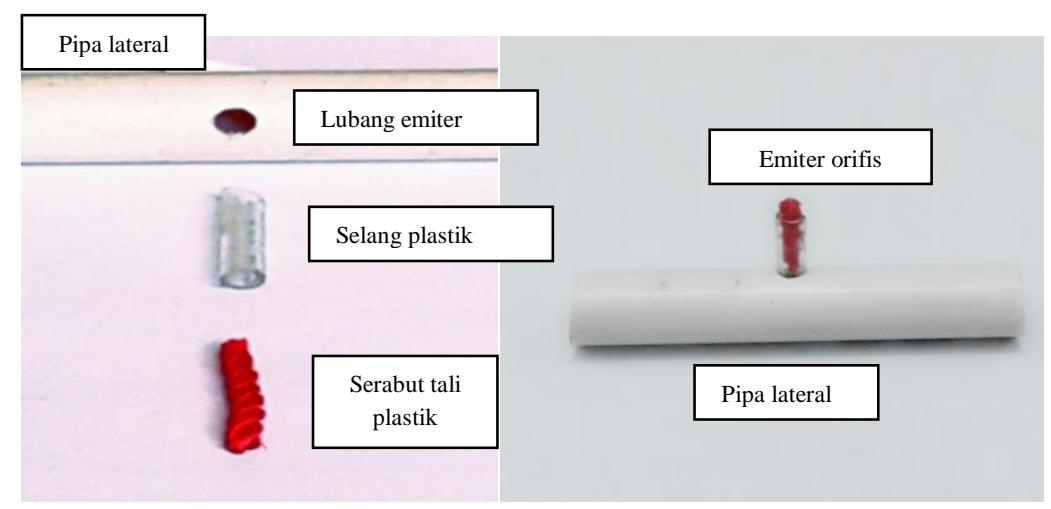

Gambar 1. Rancangan irigasi emiter tali 
Jaringan irigasi tetes emiter tali terdiri dari bak penampung air, pompa, pipa utama, pipa sub utama/manifold, jaringan lateral dari pipa PVC, dan emiter tali. Jaringan lateral dipasang sepanjang bedengan. Ukuran panjang bedengan $30 \mathrm{~m}$, lebar bedengan $0,70 \mathrm{~m}$ jarak antartitik tengah bedengan $3 \mathrm{~m}$. Jarak tanam 0,8 m x 3,0 m. Ukuran plot penelitian $30 \mathrm{~m}$ x $14 \mathrm{~m}$.

Pemupukan dilakukan dengan penaburan pupuk kandang dan pupuk dasar dengan dosis Urea 80 $\mathrm{kg} / \mathrm{ha}$, SP36 $150 \mathrm{~kg} / \mathrm{ha}$, dan $\mathrm{KCl} 150 \mathrm{~kg} / \mathrm{h}$. Sisa pupuk urea diberikan lagi pada umur tanaman 31 hari setelah tanam dengan dosis $60 \mathrm{~kg} / \mathrm{ha}$, dan terakhir diberikan pada umur 61 hari setelah tanaman dengan dosis $60 \mathrm{~kg} / \mathrm{ha}$.

Pemberian air irigasi pada pertanaman semangka dilakukan dengan menggunakan metode irigasi tetes emiter tali. Jumlah pemberian air irigasi pada tanaman semangka dengan berbagai selang waktu irigasi dan lama pemberian air irigasi dapat dilihat pada Tabel 1. Tiga hari pertama setelah penanaman pemberian air dilakukan setiap hari agar bibit semangka semuanya dapat tumbuh dengan baik. Pada hari ke-4 irigasi dilakukan sesuai perlakuan.

Tabel 1. Lama pemberian air irigasi tetes emiter tali pada selang waktu irigasi yang berbeda pada lahan pertanaman semangka

\begin{tabular}{llcc}
\hline \multicolumn{1}{c}{ Selang waktu irigasi (SWI) } & $\begin{array}{c}\text { Debit } \\
(1 / \text { jam })\end{array}$ & $\begin{array}{c}\text { Jumlah pemberian air } \\
(1 / \text { tanaman })\end{array}$ & $\begin{array}{c}\text { Lama pemberian air } \\
\text { (menit })\end{array}$ \\
\hline 1 hari & 2,7 & 0,628 & 14 \\
2 hari & 2,7 & 1,256 & 28 \\
3 hari & 2,7 & 1,884 & 42 \\
4 hari & 2,7 & 2,512 & 56 \\
\hline
\end{tabular}

Peubah yang diamati meliputi jumlah pemberian air irigasi, produksi buah semangka dan produktivitas air irigasi. Satuan setiap peubah, jumlah pemberian air irigasi dinyatakan dalam satuan liter per tanaman, produksi buah dalam kg buah per tanaman, dan produktivitas air irigasi dalam $\mathrm{kg}$ buah per meter kubik air yang diberikan.

Analisis data dilakukan dengan menggunakan analisis ragam pada taraf nyata $5 \%$ kemudian dilanjutkan dengan uji BNT pada taraf nyata $5 \%$ untuk peubah produksi dan produktivitas air, dengan jumlah sampel $10 \%$ dari populasi tanaman penelitian yang dipilih secara acak.

\section{HASIL DAN PEMBAHASAN}

Produksi, jumlah pemakaian air irigasi, dan produktivitas air irigasi tanaman semangka pada berbagai perlakuan selang waktu irigasi dapat dilihat pada Tabel 2.

Tabel 2. Produksi, jumlah pemakaian air irigasi, dan produktivitas air irigasi tanaman semangka

\begin{tabular}{ccccc}
\hline Perlakuan & $\begin{array}{c}\text { Produksi } \\
\text { (kg/tanaman) }\end{array}$ & $\begin{array}{c}\text { Produksi } \\
\text { (ton/ha) }\end{array}$ & $\begin{array}{c}\text { Jumlah } \\
\text { Pemakaian Air } \\
\text { (L/tanaman) }\end{array}$ & $\begin{array}{c}\text { Produktivitas Air } \\
\text { Irigasi }\left(\mathrm{kg} / \mathrm{m}^{3}\right)\end{array}$ \\
\hline SWI 1 hari & $5,31 \mathrm{a}$ & 21,227 & 44 & $120,61 \mathrm{a}$ \\
SWI 2 hari & $5,45 \mathrm{a}$ & 21,787 & 44 & $123,79 \mathrm{a}$ \\
SWI 3 hari & $5,17 \mathrm{a}$ & 20,667 & 44 & $117,42 \mathrm{a}$ \\
SWI 4 hari & $5,07 \mathrm{a}$ & 20,267 & 44 & $115,15 \mathrm{a}$ \\
\hline
\end{tabular}

Keterangan : SWI = Selang waktu pemberian air irigasi Nilai selajur yang diikuti dengan huruf yang sama tidak berbeda nyata pada uji BNT dengan taraf nyata $5 \%$.

Tabel 2 menunjukkan bahwa selang waktu pemberian air irigasi pada tanaman semangka dengan menggunakan irigasi tetes emiter tali tidak berpengaruh nyata terhadap produksi dan produktivitas air tanaman semangka. Rata-rata produksi tanaman semangka dengan menggunakan irigasi tetes emiter tali 
20,267-21,787 ton/ha. Produksi semangka pada penelitian ini masih tergolong sedang. FAO, 2017b) mengemukakan bahwa produksi tanaman semangka secara komersial yang tergolong baik berkisar 25 - 35 ton/ha dengan nilai produktivitas air irigasi berkisar $5-8 \mathrm{~kg} / \mathrm{m}^{3}$. Produktivitas air irigasi tanaman semangka dengan menggunakan irigasi tetes emiter tali pada keempat perlakuan selang waktu irigasi berkisar $115,15-123,79 \mathrm{~kg} / \mathrm{m}^{3}$ jauh lebih tinggi dibandingkan dengan yang telah dilaporkan oleh (FAO, 2017b) tersebut. Hal ini dapat disebabkan karena jumlah air irigasi yang diberikan ke tanaman semangka pada penelitian ini hanya 44 liter/tanaman $\left(176 \mathrm{~m}^{3} / \mathrm{ha}\right)$ selama penelitian jauh lebih kecil dibandingkan dengan pertanaman semangka yang memberikan produktivitas air irigasi $5-8 \mathrm{~kg} / \mathrm{m}^{3}$. Pada penelitian ini perhitungan kebutuhan air tanaman semangka didasarkan pada diameter pembasahan daerah perakaran hanya $80 \mathrm{~cm}$ sehingga kebutuhan air tanaman semangka rata-rata hanya 0,628 liter/hari/tanaman $\left(176 \mathrm{~m}^{3} / \mathrm{ha}\right)$. Berbeda halnya dengan perhitungan kebutuhan air tanaman semangka yang dilaporkan (FAO, 2017b) yang didasarkan pada luas daerah pertanaman atau luas daerah perakaran tanaman semangka secara keseluruhan sehingga jumlah air yang diberikan mencapai sekitar $5.000 \mathrm{~m}^{3} /$ ha tanaman semangka selama satu musim tanam.

Nilai produktivitas air irigasi tanaman semangka dengan menggunakan irigasi tetes emiter tali pada keempat perlakuan selang waktu irigasi berkisar $115,15-123,79 \mathrm{~kg} / \mathrm{m}^{3}$ masih sesuai dengan yang dilaporkan oleh (Erdem et al., 2001) yang menyatakan bahwa produktivitas air irigasi tanaman semangka dan produktivitas air total tanaman semangka berkisar $24,31-197,89 \mathrm{~kg} / \mathrm{m}^{3}$ dan $17,17-30,30 \mathrm{~kg} / \mathrm{m}^{3}$ secara berturut-turut. Rashidi \& Gholami, (2008) mengemukakan bahwa perbedaan produktivitas air irigasi tanaman ditentukan/tergantung pada iklim dan pengelolaan air irigasi antara satu daerah dengan dengan daerah yang lainnya. Selanjutnya Kuscu et al., (2015) mengemukakan bahwa perbedaan produktivitas air irigasi tanaman semangka dapat disebabkan oleh faktor perbedaan varietas tanaman, sistem irigasi, pemupukan, tanah dan iklim.

Karakteristik Tanah, Kadar Air Tanah Sebelum dan Setelah Irigasi. Karakteristik tanah lapasian atas pada kedalaman lapisan tanah $0-30 \mathrm{~cm}$ di lokasi petak percobaan berupa tekstur liat dengan kandungan pasir 31,2\%, debu 20,0\% dan liat 48,8\%\%. Kadar air tanah pada kondisi kapasitas lapang dan pada kondisi titik layu permanen berturut-turut 40,50 dan $13,91 \%$, ruang pori $56,98 \%$ dan bobot isi tanah $1,14 \mathrm{~g} / \mathrm{cm}^{3}$. Kadar air tanah sebelum irigasi dan kadar air tanah setelah 2 jam irigasi sampai pada kedalaman lapisan tanah $30 \mathrm{~cm}$ dapat dilihat pada Tabel 3 .

Tabel 3. Rata-rata kadar air tanah (\% berat) sebelum dan setelah irigasi pada selang waktu irigasi yang berbeda

\begin{tabular}{ccc}
\hline Perlakuan & $\begin{array}{c}\text { Kadar air tanah } \\
\text { Sebelum irigasi }(\%)\end{array}$ & $\begin{array}{c}\text { Kadar air tanah } \\
\text { Setelah irigasi (\%) }\end{array}$ \\
\hline SWI 1 hari & 23,23 & 29,59 \\
SWI 2 hari & 23,80 & 30,70 \\
SWI 3 hari & 23,88 & 29,93 \\
SWI 4 hari & 23,65 & 29,94 \\
\hline
\end{tabular}

Katerangan : SWI $=$ Selang waktu pemberian air irigasi

Kadar air tanah di daerah perakaran tanaman sebelum irigasi dapat menunjukkan bahwa apakah kadar air tanah tersebut masih dalam kondisi tersedia atau tidak tersedia bagi tanaman. Tabel 3 menunjukan kadar air tanah sebelum irigasi pada semua perlakuan selang waktu irigasi berkisar 23,23-23,88\% masih berada pada kondisi tersedia bagi tanaman sehingga tanaman semangka pada semua perlakuan masih dapat tumbuh dan berproduksi cukup baik. Rata-rata kadar air tanah di daerah perakaran setelah 2 jam irigasi pada keempat selang waktu irigasi berkisar 29,59-30,70\% belum mendekati kadar air tanah pada kondisi kapasitas lapang di daerah perakaran sebersar 40,50\%. Kondisi kadar air tanah yang belum mendekati level kadar air tanah pada kondisi kapasitas lapang setelah irigasi dapat merupakan salah satu faktor penyebab 
belum tercapainya kisaran produksi semangka yang tergolong baik seperti yang dikemukakan (FAO, 2017b). Berdasarkan hal ini produksi tanaman semangka masih dapat ditingkatkan dengan meningkatkan jumlah pemberian air irigasi ke tanaman semangka melebihi 44 1/tanaman per musim sampai kondisi kadar air tanah hampir mendekati kondisi kapasitas lapang setelah irigasi.

\section{KESIMPULAN DAN SARAN}

Selang waktu irigasi sampai 4 hari pada lahan bertekstur liat dengan menggunakan irigasi tetes emiter tali tidak berpengaruh nyata terhadap produksi dan produktivitas air irigasi tanaman semangka. Selang waktu irigasi yang baik pada lahan bertekstur liat dengan menggunakan irigasi tetes emiter tali pada tanaman semangka yaitu 4 hari dengan prodktivitas air irigasi tanaman semangka mencapai $115,15 \mathrm{~kg} / \mathrm{m}^{3}$.

Penelitian lanjutan perlu dilakukan dengan perbedaan persentase luas pembasahan areal pertanaman semangka di lahan terbuka untuk perhitungan jumlah air irigasi yang akan diberikan ke tanaman sehingga diperoleh nilai produksi dan produktivias air irigasi yang optimal.

\section{UCAPAN TERIMA KASIH}

Penulis menyampaikan terima kasih kepada Unit Penelitian dan Pengabdian kepada Masyarakat (UPPM) Politeknik Negeri Lampung atas bantuan dana yang telah diberikan kepada penulis sehingga penelitian ini dapat dilaksanakan dengan baik hingga pelaporan.

\section{DAFTAR PUSTAKA}

Badan Pusat Statistik 2018. Provinsi Lampung Dalam Angka 2018. 1-362.

Erdem, Y., Yuksel, A.N. \& Orta, A.H. 2001. The Effects of Deficit Irrigation on Watermelon Yield, Water Use and Quality Characteristics. Pakistan Journal of Biological Sciences, 4(7): 785-789.

FAO 2017a. FAOSTAT: Countries by Commodity.

FAO 2017b. Watermelon: Land and Water. Tersedia di http://www.fao.org/land-water/databases-andsoftware/crop-information/watermelon/en/.

Fernandes, C.N.V., Azevedo, B.M. de, Neto, J.R.N., Viana, Thales Vinícius de Araújo, G.G. de \& Sousa 2014. Irrigation and fertigation frequencies with nitrogen in the watermelon culture. Brangantia, 73(3): 1-6.

Idrus, M., Surapto, S. \& Raharjo, I. 2012. Penerapan Irigasi Tetes Bawah Permukaan Dan Berbagai Selang Waktu Irigasi Pada Tanaman Semangka. Jurnal Ilmiah Teknik Pertanian, 4(1): 1-10.

Irmak, S., Odhiambo, L.O., Kranz, W.L. \& Eisenhauer, D.E. 2011. Irrigation Efficiency and Uniformity, and Crop Water Use Efficiency. Biological Systems Engineering: Papers and Publications, 451.

Jadavi, A., Coelho, E.F. \& Miranda, J.H. De 2013. Efficiency of water application of irrigation systems based on microsprinkling in banana plantations. colation and water extra, 70(3): 139-146.

Kuscu, H., Aydinol, P., Buyukcangaz, H. \& Demir, A.O. 2015. Deficit irrigation effects on watermelon ( Citrullus vulgaris ) in a sub humid environment. The Journal of Animal \& Plant Sciences, 25(6): $1652-1659$.

Pejić, B., Mačkić, K., Pavković, S. \& Mašić, B.L. 2016. Water-Yield Relations of Drip Irrigated Watermelon In. Contemporary Agriculture, 65(1): 53-59.

Rashidi, M. \& Gholami, M. 2008. Review of Crop Water Productivity Values for Tomato, Potato, Melon , Watermelon and Cantaloupe in Iran. International Journal of Agriculture and Biology, 10(4): 432436. 